1 ANALYTICAL SCIENCE

3 \& TECHNOLOGY

Vol. 26, No. 2, 113-119, 2013

http://dx.doi.org/10.5806/AST.2013.26.2.113

\title{
Contents characteristics of polybrominated diphenyl ethers (PBDEs) in indoor household dust
}

\author{
Kyeo-Keun Kim ${ }^{\star}$ \\ Department of Environmental Engineering, Cheongju University, Cheongju 360-764, Korea \\ (Received August 7, 2012; Revised February 4, 2013; Accepted March 7, 2013)
}

\section{실내 먼지 중 브롬화난연제 함유특성 연구 \\ 김 교 근` \\ 청주대학교 환경공학과}

(2012. 8. 7. 접수, 2013. 2. 4. 수정, 2013. 3. 7. 승인)

\begin{abstract}
The objective of this study was to understand the content characteristic of polybrominated biphenyl ethers in indoor household dust. Polybrominated diphenyl ethers (PBDEs) are widely used as additive brominated flame retardants (BFR) in electrical and electronic equipment, and insulation in the indoor environment, and may be released indoors via volatilization or as dusts. The indoor household dust samples were collected from January to December in 2011 and measured for the concentrations, congener profiles and possible sources of PBDEs. The concentrations of 22 congeners of PBDEs (the sum of PBDEs 47, 49, 66, 71, 77, 85, 99, 100, $119,126,138,153,154,156,183,184,191,196,197,206,207$ and 209) were 35.22 575.88 ng/g for apartment dust samples and $524.44 \mathrm{ng} / \mathrm{g}$ for laboratory dust sample. The eight congeners of BDE-47, 153, 183, 196, 197 , 206, 207, and 209 are detected in the more than $1 \mathrm{ng} / \mathrm{g}$. The three congeners of BDE-206, 207 and 209 in all dust samples were detected.

요 약: 본 연구에서는 전기전자제품에 브롬화난연제로 널리 사용되고 있는 폴리브롬화디페닐에테르가 우리의 생활에서 어떻게 배출되는지 파악하고자 가정에서 발생되는 먼지 시료를 2011년 1월부터 12월까 지 채취 - 분석하여 이성체 함량특성을 조사하였다. 아파트와 실험실에서 채취한 실내 먼지 중 총 22 종 의 PBDEs $(47,49,66,71,77,85,99,100,119,126,138,153,154,156,183,184,191,196,197,206$, $207,209)$ 를 분석하여 정량한 결과, 아파트 실내 먼지에서 검출된 PBDEs 농도는 $35.22 ~ 575.88 \mathrm{ng} / \mathrm{g}$ 으로 나타났으며, 실험실에서 겨울에 채취된 먼지 중에서는 PBDEs가 $524.44 \mathrm{ng} / \mathrm{g}$ 검출되었다. 분석시료 중 1 $\mathrm{ng} / \mathrm{g}$ 이상 검출된 이성체는 BDE-47, 153, 183, 196, 197, 206, 207, 209 등 8종으로 조사되었으며, 모든 시료에서는 BDE-206, 207, 209 3종의 이성체가 검출되었다.
\end{abstract}

Key words: PBDE, BFR, household dust

Corresponding author

Phone : +82-(0)43-229-8574 Fax : +82-(0)43-229-8906

E-mail : kyeokim@cju.ac.kr 


\section{1. 서 론}

잔류성 유기오염물질(POPs, persistent organic pollutants)은 환경 중에서 독성, 잔류성, 생물 농축성 및 장거리이동성 등의 특징을 가진 물질로서 인체 및 생태계에 독성을 나타내는 다이옥신, 폴리염화비페닐 류(PCBs, polychlorinated biphenyls) 및 유기염소계 농 약류 등이 있다. 이들 물질은 환경내에서 분해되지 않 고 먹이사슬을 통하여 동물의 체내에 축적되며 면역 체계교란, 중추신경계 손상 등을 초래하는 물질로 알 려져 있다. 이들 물질의 저감 또는 근절을 목표로 스 톡홀름 협약이 2004년 발효되었고, 우리나라는 2007 년에 비준하여 현재 잔류성유기오염물질관리법을 통 하여 잔류성 유기오염물질의 생산, 사용 및 배출을 관 리하고 있다. ${ }^{1-3}$ 또한, 스톡홀름 협약에서는 이들 12 종 (dioxins, PCBs 및 DDT, aldrin, hexachlorobenzene 등 유기염소계 농약류) 이외에 잔류성유기오염물질의 특 성을 가지는 화학물질을 검토하여 2009년 제4차 스톡 홀름협약 당사국 총회에서 추가로 9개 물질이 등재되 어 2010년 5월부터 규제가 되고 있다. 새롭게 잔류성 유기오염물질로 등재된 화학물질은 클로로테콘 (chlorodecone), 린단(lindane), 핵사클로로사이클로핵산 (hexachlorocyclohexane, $\alpha-\mathrm{HCH}$ 및 $\beta-\mathrm{HCH}$ ), 펜타브로 모디페닐에테르(pentabromodiphenyl ether), 옥타브로 모디페닐에테르(octabromodiphenyl ether), 폴리브롬화 비페닐(polybromoinated biphenyl), 펜타클로로벤젠 (pentachlorobenzene), 과불화합물(perfluoro compounds) 이다. ${ }^{1-3}$

최근 플라스틱의 용도가 건축용, 자동차용, 전기·전 자제품, 항공기, 선박 등으로 광범위하게 확대됨에 따 라, 화재발생시 안전을 고려하여 이들 제품의 난연화 필요성이 지속적으로 증대되고 있다. 플라스틱은 대부 분 탄소, 수소, 산소로 구성된 유기물질로 연소하기 쉬운 성질을 가지고 있어서, 이와 같은 성질을 물리 화학적으로 개질하여 잘 타지 못하도록 첨가하는 물 질을 난연제라고 한다. ${ }^{3-5}$ 신규 POPs 물질로 등재된 폴리브롬화디페닐이써(PBDEs, polybrominated diphenyl ethers)는 플라스틱, 전기 - 전자회로소자, $\mathrm{TV}$, 건축자재, 섬유 등의 가연성 물질 또는 재료에 첨가하여 발화를 방지하거나 지연 시킬 목적으로 사용된 대표적인 브 롬화난연제 중 하나이다. PBDEs는 브롬화탄화수소류 중의 하나로 비페닐기의 수소가 브롬으로 치환되어 형성된다. PBDEs는 자연적으로 발생되지 않는 것으 로 알려져 있으나, $\mathrm{C}_{12} \mathrm{H}_{(10-\mathrm{x}-\mathrm{y})} \mathrm{Br}_{(\mathrm{x}+\mathrm{y})} \mathrm{O}$ 의 분자식을 가지
며 페닐기의 브롬원자의 위치와 수에 따라 209종의 동족체가 존재한다. PBDEs는 급성독성이 낮으며 결 합된 브롬수에 따라 독성이 다르며 Deca-BDE는 미국 ATSDR (Agency for Toxic Substances and Disease Registry)에서 B2(인간에게 암을 일으킬 가능성이 있 는 물질) 등급 물질로 관리하고 있다. 특히, 산업화에 따라 전기 - 전자 제품의 사용이 급격하게 증가되고 있 으며, 이로 인한 난연제 화합물의 사용 및 생산량도 증가되고 있는 실정이다. 또한, 전기전자제품의 분리, 파쇄 등의 재활용과정이나 소각 등의 폐기과정에서 공기중으로 배출되는 등의 환경오염도 점점 더 증대 되고 있는 실정이다. ${ }^{4-6}$

따라서, 스톡홀름 협약에서는 2010년부터 사용을 제한하는 규제가 시작되었으며, 유럽연합에서는 2006 년부터 전기 - 전자제품에 함유된 브롬화난연제의 재활 용을 규제하고자 RoHS (The Restriction of the use of certain Hazardous Substances in electrical and electronic equipment) 환경규제 대상물질로 관리하고 있다. 그러 므로 본 연구에서는 국제적으로 관심의 대상이 되고 있는 브롬화난연제의 효율적인 관리를 위하여 가정 및 실험실 등의 실내공간에서 사용하고 있는 전기전 자제품에 함유된 브롬화난연제가 우리의 생활에서 어 떻게 배출되는지 파악하고자 가정에서 발생되는 먼지 시료를 계절별로 채취 - 분석하여 배출특성을 조사하였 다. 또한, 우리나라에서 주로 사용되고 있는 전기 - 전 자제품 중 브롬화난연제 함유특성을 토대로 향후 전 기 - 전자제품 폐기물의 재활용 및 최종 처리시 적정처 리 방안을 마련하기 위한 기초자료로 활용될 것이다.

\section{2. 연구내용 및 실험방법}

\section{1. 시료채취 및 분석}

경기도 소재의 아파트에서 2011년 1월부터 12월까 지 집안에서 발생되는 먼지 시료를 채집하였다(Fig. 1). 가정에서 발생된 먼지는 Table 1과 같이 봄, 여름, 가을, 겨울로 구분하여 3 개월 동안 채집된 청소기의 먼지를 수집하여 협잡물을 제거하고 500 mesh 체로 쳐서 분석 시료를 준비하였다. 또한, $\mathrm{GC} / \mathrm{ECD}$ (Gas Chromatography/Electron Capture Detector) 등 8종의 분석기기가 설치된 실험실에서 먼지 시료를 채취하여 PBDEs 배출 특성을 비교하였다. 또한, 시판되고 있는 전기 - 전자제품에 사용된 난연제의 종류 및 양은 기업 의 자료로 정확하게 확인되지 않아 제품에 주로 많이 사용되고 있는 제품으로 알려진 Penta-BDE(DE-71 ${ }^{\mathrm{TM}}$, 


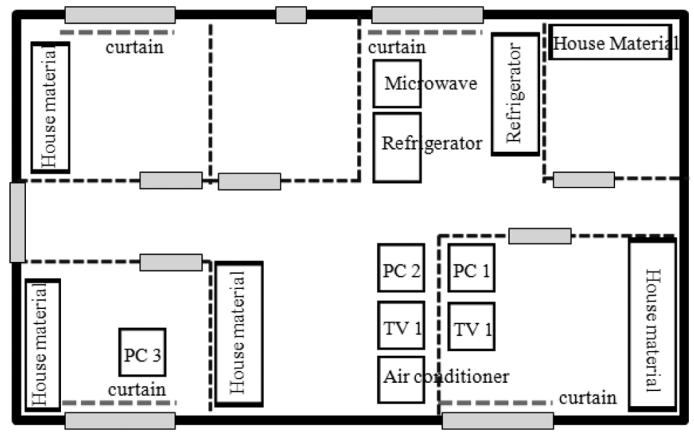

(a) Apartment

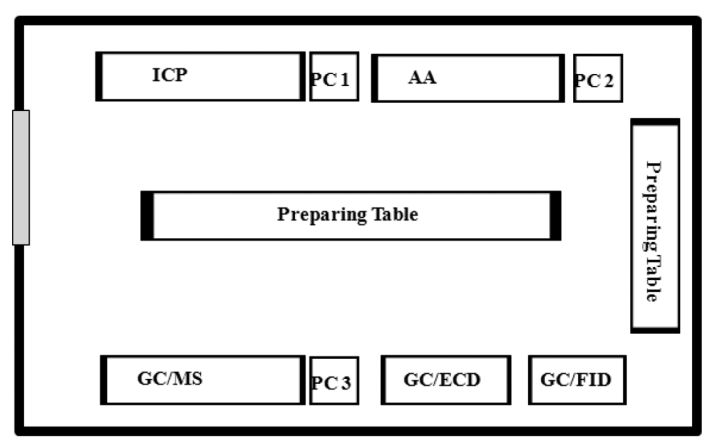

(b) Laboratory

Fig. 1. Model room experiments to investigate BFR emission from products.

Bromkal 70-5DE ${ }^{\mathrm{TM}}$ )와 Deca-BDE(Saytex 102藏, Bromkal $\left.82-\mathrm{OED}^{\mathrm{TM}}\right)$ 의 구성성분과 비교 - 검토 하였다.

\section{2. 시료분석}

채취된 먼지 시료는 환경부 POPs 공정시험기준 ${ }^{\text {의 }}$ 토양 중 브롬화난연제 분석방법을 참고로하여 동위원 소희석법과 HRGC/HRMS (High Resolution Gas Chromatography/High Resolution Mass Spectrometry)로 분 석하였다. 채취된 먼지시료는 전량 톨루엔 $500 \mathrm{~mL}$ 로 24 시간 동안 속실렛 추출하였다. 추출액은 약 $2 \mathrm{~mL}$ 까 지 농축한 다음, 전량 헥산으로 용매전환 후 황산처리 를 하였으며 다층실리카겔 컬럼(중성-염기성-중성-산
성-중성 순으로 충진), 알루미나 컬럼 정제 작업을 수 행하였다. 기기분석은 $50 \mu \mathrm{L}$ 까지 농축한 시료에 실린지 첨가용 내부표준물질로 ${ }^{13} \mathrm{C}-\mathrm{BDE}-138$ 을 $2 \mathrm{ng}$ 첨가하고 DB-5HT $(15 \mathrm{~m} \times 0.25 \mathrm{~mm}$ i.d., $0.1 \mu \mathrm{m}$, J\&W Scientific) 컬럼을 이용하여 HRGC/HRMS로 분해능 10,000 이상 $(10 \%$ valley)에서 EI-SIM (Electron impact-selected ion monitoring) 모드로 수행하였다.

\section{3. 표준용액 및 정도관리}

먼지 중 PBDEs 분석을 위해 Native(분석하고자 하 는 대상 물질의 표준물질), Labeled(추출 및 정제 전에 일정한 농도로 주입하는 물질로 분석에 의한 손실정도 를 확인하기 위한 표준물질), Syringe standards (Labelled 표준물질의 회수율을 확인하게 위해 분석직전에 주입 하는 표준물질) 그리고 Calibration standard $(\mathrm{CS}$, 정 량 용 표준물질)이 사용되었다. Native standard는 13종과 labelled standard 4,4'-dibromo-octafluorobiphenyl (DBOFB) 이 $50 \mathrm{ng} / \mathrm{mL} 450 \mathrm{ng} / \mathrm{mL}$ 의 5 단계 농도 범위로 검량 선을 작성하여 정량하였으며, PCBs 209(200 ng)이 syringe spike standard로 사용되었다. 다음 Table 2에 분석조건을 정리하였으며, 실험실에서 용매나 초자에 의한 오염 여부를 검토하기 위하여 바탕시료를 분석 하였다. PBDEs 분석에 첨가된 13 종의 ${ }^{13} \mathrm{C}$-labelled 이

Table 2. Analytical conditions of HRGC/HRMS

\begin{tabular}{ll}
\hline \hline \multicolumn{1}{c}{ Item } & \multicolumn{1}{c}{ HRGC/HRMS } \\
\hline Column & DB-5HT $(15 \mathrm{~m} \times 0.25 \mathrm{~mm} \times 0.1 \mu \mathrm{m})$ \\
Injection volume & $1 \mu \mathrm{L}$ (splitless) \\
Carrier gas & Helium $(99.9999 \%)$ at $1.0 \mathrm{~mL} / \mathrm{min}$. \\
Injection temp. & $270{ }^{\circ} \mathrm{C}$ \\
Transfer line temp. $270{ }^{\circ} \mathrm{C}$ \\
& $100{ }^{\circ} \mathrm{C}(5 \mathrm{~min}) \rightarrow 4{ }^{\circ} \mathrm{C} / \mathrm{min}$ to $200{ }^{\circ} \mathrm{C}$ \\
Oven temp. & $(5 \mathrm{~min}) \rightarrow 10{ }^{\circ} \mathrm{C} / \mathrm{min}$ to $300{ }^{\circ} \mathrm{C}$ for $10 \mathrm{~min}$ \\
Ionization mode & $\mathrm{EI}$ \\
Detection & $\mathrm{SIM}$ \\
Ionization voltage & $35 \mathrm{eV}$ \\
Resolution & $>10,000(10 \%$ valley $)$ \\
\hline
\end{tabular}

Table 1. Summary of samples

\begin{tabular}{cllcl}
\hline \hline \multicolumn{2}{c}{ Sample No. } & Sampling period & Sample amounts $(\mathrm{g})$ & Comments \\
\hline \multirow{4}{*}{ House } & Sample-1 & January March & 8.952 & Spring season \\
& Sample-2 & April July & 8.834 & Summer season \\
& Sample-3 & July October & 12.917 & Fall season \\
& Sample-4 & November December & 9.427 & Winter season \\
\hline \multirow{2}{*}{ Laboratory } & Sample-5 & December & 6.285 & Winter season \\
\hline
\end{tabular}


성질체의 평균 회수율은 50 80\% 범위로 POPs 공정 시험기준에서 제시한 25 150\%를 만족하였다. 검출한 계는 $\mathrm{S} / \mathrm{N}$ 비 3 이상으로 하였으며, 각각 동족체별로 mono-, di-, tri-BDE는 $1 \mathrm{pg} / \mathrm{g}$, tetra-, penta-BDE는 10 $\mathrm{pg} / \mathrm{g}$, hexa-, hepta-BDEs는 $20 \mathrm{pg} / \mathrm{g}$, octa-, nona-BDEs $20 \mathrm{pg} / \mathrm{g}$ 그리고 deca-BDEs는 $30 \mathrm{pg} / \mathrm{g}$ 이었다.

\section{3. 결과 및 고찰}

\section{1. 실내 먼지 중 $\mathrm{PBDEs}$ 분석결과}

아파트에서 채취한 4건의 시료와 실험실에서 채취 한 1 건의 실내 먼지 중 $\mathrm{PBDEs}$ 분석결과를 다음의 Table 3에 정리하였다. 분석대상 항목은 Tetra-BDE에서 Deca-BDE까지 총 22종의 PBDEs (IUPAC (International Union of Pure and Applied Chemistry) No. 47, 49, 66, $71,77,85,99,100,119,126,138,153,154,156,183$, $184,191,196,197,206,207,209)$ 를 분석하여 정량하 였다.
Table 3에 나타난 바와 같이 실내 아파트의 먼지에 서 검출된 PBDEs 농도는 $35.22 ~ 575.88 \mathrm{ng} / \mathrm{g}$ 으로 나 타났으며, 이성체의 배출패턴을 비교하기 위해 실험실 에서 겨울에 채취된 먼지 중에서는 PBDEs가 524.44 $\mathrm{ng} / \mathrm{g}$ 검출되었다. PBDEs가 가장 높은 농도로 검출된 시료는 1월 3월까지 채취된 봄철시료로 $575.88 \mathrm{ng} / \mathrm{g}$ 으로 나타났으며, 다음으로 11월에서 12월에 채취된 시료에서 $212.15 \mathrm{ng} / \mathrm{g}$ 이 채취되었고, 8 월에서 10 월 중 에 채취된 시료 $86.46 \mathrm{ng} / \mathrm{g}$ 으로 나타났다. 또한, 채취 먼지 중 $\mathrm{PBDEs}$ 가 가장 낮게 검출된 시료는 4월에서 7월에 채취된 시료로 $35.22 \mathrm{ng} / \mathrm{g}$ 이 검출되어, 환기가 비교적 잘되는 계절에 검출된 $\mathrm{PBDEs}$ 의 농도가 낮은 것을 알 수 있었다.

본 연구에서 검출된 실내 먼지 중 $\mathrm{PBDEs}$ 검출농도 를 발표된 연구결과와 비교해 보면 Table 4와 같다. Table 4에 나타난 바와 같이 영국은 927 54,628 ng/g 범위로 검출되었으며 다음으로 미국은 425 33,270 ng/ $\mathrm{g}$ 범위로 나타났다. 또한 호주의 경우에는 79 19,159

Table 3. Concentrations of PBDEs in dust

(unit : ng/g)

\begin{tabular}{|c|c|c|c|c|c|}
\hline \multirow[b]{2}{*}{ Congener } & \multicolumn{4}{|c|}{ House dust } & \multirow{2}{*}{$\begin{array}{l}\text { Lab. dust } \\
\text { sample-5 }\end{array}$} \\
\hline & $\begin{array}{c}\text { Spring } \\
\text { sample-1 }\end{array}$ & $\begin{array}{l}\text { Summer } \\
\text { sample-2 }\end{array}$ & $\begin{array}{c}\text { Fall } \\
\text { sample-3 }\end{array}$ & $\begin{array}{c}\text { Winter } \\
\text { sample-4 }\end{array}$ & \\
\hline 49-Tetra-BDE & 0.69 & 0.00 & 0.04 & 0.26 & 0.50 \\
\hline 71-Tetra-BDE & 0.71 & 0.00 & 0.04 & 0.27 & 0.52 \\
\hline 47-Tetra-BDE & 6.98 & 0.02 & 0.45 & 1.40 & 2.72 \\
\hline 66-Tetra-BDE & N.D. & 0.00 & 0.02 & 0.04 & 0.11 \\
\hline 77-Tetra-BDE & N.D. & 0.01 & 0.00 & 0.01 & N.D. \\
\hline 100-Penta-BDE & 9.08 & 0.03 & 1.46 & 11.87 & 17.17 \\
\hline 119-Penta-BDE & N.D. & N.D. & 0.03 & 0.08 & 0.27 \\
\hline 99-Penta-BDE & 3.97 & 0.04 & 0.85 & 4.14 & 3.66 \\
\hline 85-Penta-BDE & N.D. & 0.01 & N.D. & N.D. & N.D. \\
\hline 126-Penta-BDE & N.D. & 0.01 & N.D. & 0.02 & N.D. \\
\hline 154-Hexa-BDE & 0.43 & 0.02 & 0.11 & 0.48 & 0.44 \\
\hline 153-Hexa-BDE & 1.03 & 0.03 & 0.21 & 0.85 & 1.20 \\
\hline 138-Hexa-BDE & 0.04 & 0.02 & N.D. & N.D. & 0.00 \\
\hline 156-Hexa-BDE & N.D. & 0.02 & N.D. & 0.01 & N.D. \\
\hline 184-Hepta-BDE & 0.21 & 0.01 & 0.02 & 0.20 & 0.53 \\
\hline 183-Hepta-BDE & 2.60 & 0.09 & 0.71 & 3.11 & 4.28 \\
\hline 191-Hepta-BDE & 0.50 & 0.02 & 0.02 & 0.10 & 0.28 \\
\hline 196-Octa-BDE & 3.46 & 0.11 & 0.22 & 0.43 & 0.71 \\
\hline 197-Octa-BDE & 4.32 & 0.15 & 0.47 & 1.67 & 2.79 \\
\hline 206-Nona-BDE & 67.72 & 1.52 & 6.10 & 13.99 & 30.00 \\
\hline 207-Nona-BDE & 76.32 & 2.87 & 5.76 & 13.38 & 32.56 \\
\hline 209-Deca-BDE & 397.81 & 30.23 & 69.93 & 159.82 & 426.68 \\
\hline Total & 575.88 & 35.22 & 86.46 & 212.15 & 524.44 \\
\hline
\end{tabular}


Table 4. Comparison the PBDEs concentration in house dust ${ }^{6-10}$

\begin{tabular}{|c|c|c|c|}
\hline \multirow{2}{*}{ Country } & \multirow{2}{*}{ Sample } & Congeners & \multirow{2}{*}{$\begin{array}{c}\text { Concentration } \\
(\mathrm{ng} / \mathrm{g})\end{array}$} \\
\hline & & IUPAC No. & \\
\hline Canada & House dust & PBDEs 17, 28, 47, 66, 100, 99, 85, 154, 153, 138, 183, 190, 209 & $123 \sim 182$ \\
\hline China & House dust & PBDEs 28, 47, 66, 100, 99, 85, 154, 153, 183, 290 & $181 \sim 10,543$ \\
\hline China & Office dust & PBDEs 28, 47, 66, 100, 99, 85, 154, 153, 183, 290 & $1,724 \sim 4,422$ \\
\hline China & Outdoor dust & PBDEs 28, 47, 66, 100, 99, 85, 154, 153, 183, 290 & $95 \sim 3,332$ \\
\hline Germany & House dust & PBDEs 47, 100, 99, 154, 153, 183, 290 & N.D 339 \\
\hline Australia & House dust & PBDEs 47, 100, 99, 154, 153, 183, 290 & $79 \sim 19,159$ \\
\hline Britain & House dust & PBDEs 47, 100, 99, 154, 153, 183, 290 & $927 \sim 54,628$ \\
\hline USA & House dust & PBDEs 47, 100, 99, 154, 153, 183, 290 & $425 \sim 33,270$ \\
\hline This study & House \& Laboratory dust & $\begin{array}{l}\text { PBDEs } 47,49,66,71,77,85,99,100,119,126,138,153,154,156, \\
183,184,191,196,197,206,207,209\end{array}$ & $35.22 \sim 575.88$ \\
\hline
\end{tabular}

$\mathrm{ng} / \mathrm{g}$ 으로 보고되었으며, 중국은 $181 \sim 10,543 \mathrm{ng} / \mathrm{g}$ 범위 로 보고되었다. 반면에 독일은 $339 \mathrm{ng} / \mathrm{g}$ 정도로 보고 되었으며, ${ }^{8-12}$ 본 연구결과에서 가장 높은 농도로 검출 된 PBDEs 총합은 $575.88 \mathrm{ng} / \mathrm{g}$ 으로서 미국, 영국, 호 주에 비해 낮은 수준으로 나타나, 난연제가 생산되기 시작한 초기에는 미국 등 선진국을 중심으로 사용되 어 현재 미국이 가장 난연제에 많이 노출되어 있다는 연구결과와 일치하였다. ${ }^{13-15}$

\section{2. 이성체 분포특성}

본 연구에서는 분석대상 22 종의 이성체의 분포특성
을 검토하고, 분석시료에서 주로 검출된 8 종의 이성체 를 중심으로 외국의 검출결과와 이성체 분포특성을 비교 - 검토하였다. 실내 먼지 중 22종의 PBDEs 분석 결과, 시료 중 $1 \mathrm{ng} / \mathrm{g}$ 이상 검출된 이성체는 BDE-47, $153,183,196,197,206,207,209$ 등 8종으로 조사되 었으며, 모든 분석 시료에서 BDE-206, 207, 209은 검 출되었으며, 일부 이성체들은 불검출 되기도 하였다. Fig. 2에 나타난 바와 같이 시료별로 주요 3종의 이성 체 (BDE-206, 207, 209)의 분포특성을 보면, BDE-209 가 69.1 86\%로 배출되었으며, BDE-207이 6 13\%, 그 리고 BDE-206이 4 12\% 범위로 배출되었다. 또한,
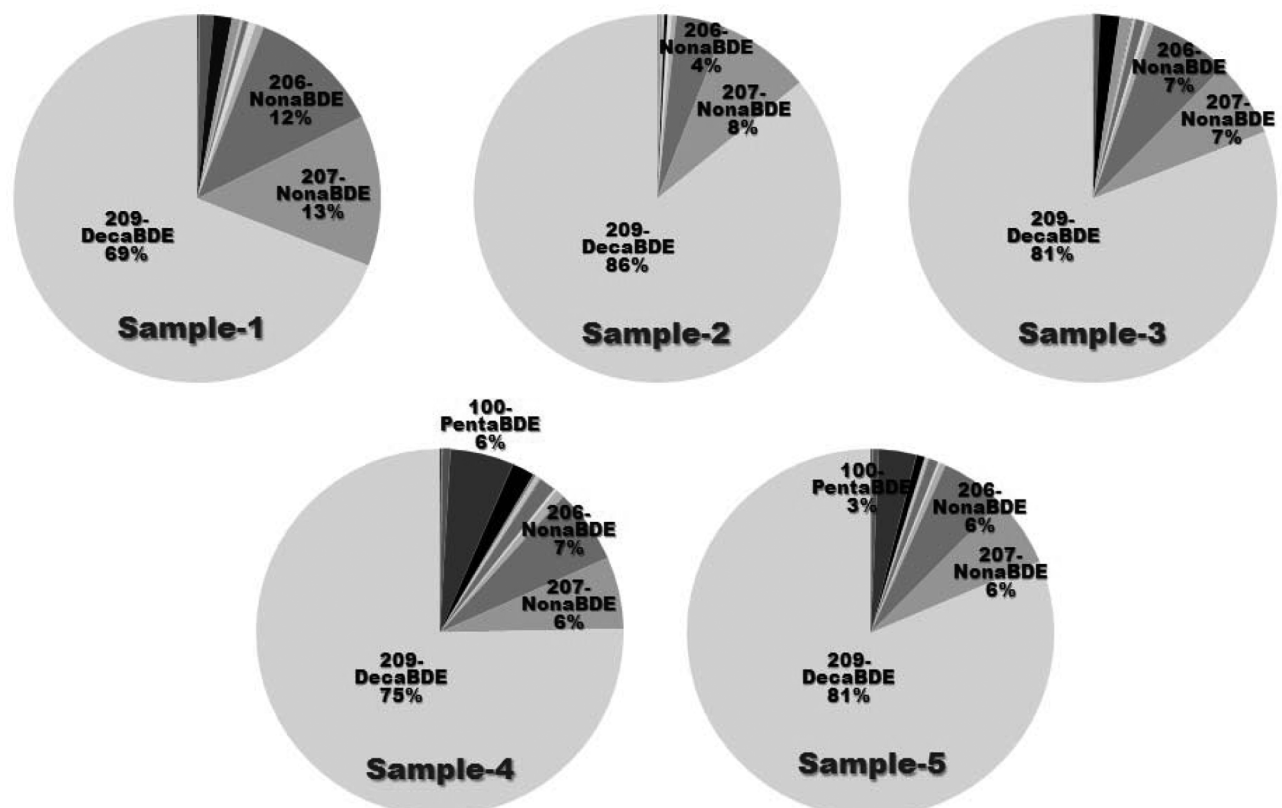

Fig. 2. Main congeners of collected samples.

Vol. 26, No. 2, 2013 
Sample-1의 경우에는 주요 3종의 이성체이외에 BDE47 이 다음 순으로 $1.2 \%$ 정도 차지하는 것으로 나타났 다. 이는 기존에 분석한 국내 가전제품 중 함유 PBDEs 의 대부분이 $\mathrm{BDE}-209$ 인 것과 일치하는 결과이다.

외국의 실내 먼지 중 주요 이성체 분포특성을 살펴 보면 다음 Fig. 3과 같다. 그림에 나타난 바와 같이 본 연구 결과가 기존의 연구결과에 비해 낮게 나타났 다. 특히 미국의 실내 먼지에서는 BDE-209 다음으로

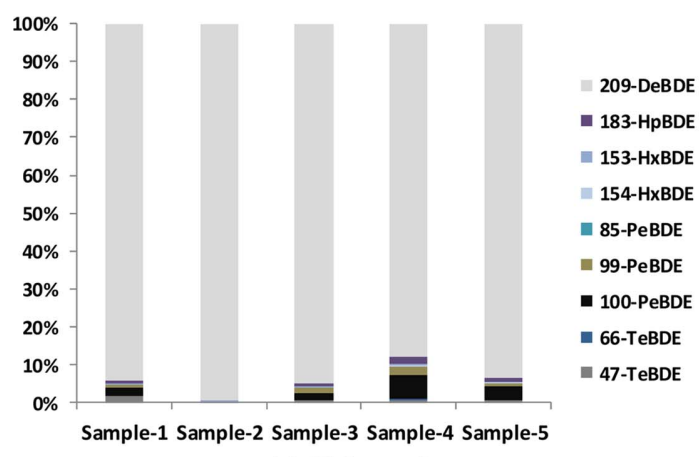

(a) This study

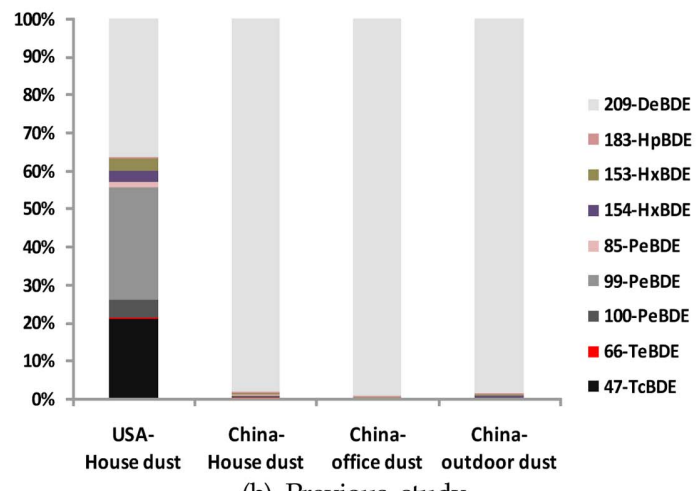

(b) Previous study

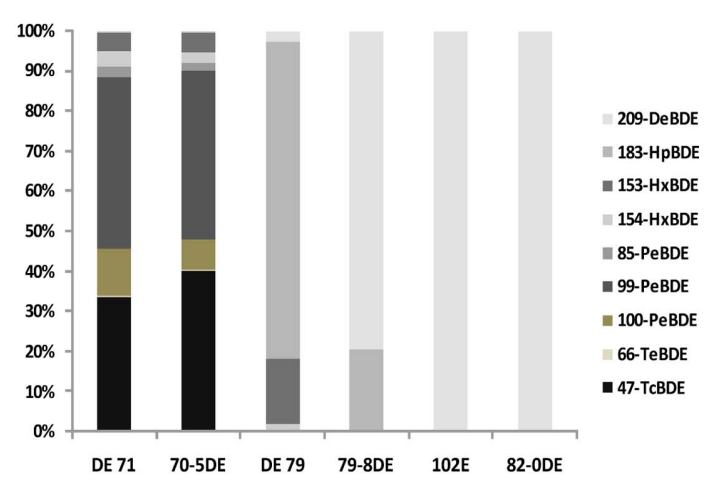

(c) PBDE product

Fig. 3. Comparison the congener pattern of PBDEs technical products.
$\mathrm{BDE}-47$ 이 차지하는 비율이 높은 것으로 조사되어 국 내의 검출패턴과는 다른 것으로 조사되었으나, 중국의 실내 먼지의 배출패턴은 거의 대부분 BDE-209이 배 출되는 것으로 조사되어 국내의 검출패턴과 일치하는 것으로 조사되었다. 그러므로 중국에서 채취하여 분석 한 전기전자제품시료는 주로 Deca-BDE가 사용된 제 품인 것으로 판단된다.

또한, Fig. 3에 나타난 바와 같이 상품으로 사용되 는 Penta-BDE(DE 71, 70-5DE)의 주요 이성체는 $\mathrm{BDE}-$ $47,99,100$ 이며, Octa-BDE 제품의 주요 이성체는 $\mathrm{BDE}-183$ 이다. 가장 많이 사용되고 있는 Deca-BDE는 $95 \%$ 이상이 $102 \mathrm{E}$ 나 $82-\mathrm{OED}$ 로 구성되어있다. 국내의 분석한 먼지 시료의 이성체 패턴은 BDE-209의 비율이 5 개 시료 평균 $78.4 \%$ 를 차지하고 있어 대부분 Deca$\mathrm{BDE}$ 로 구성된 $102 \mathrm{E}$ (96\% 이상)나 $82-\mathrm{OED}(91 \%$ 이상 $)$ 의 영향을 받은 것으로 판단되었으며, 미국의 먼지 시 료는 IUPAC No. 99, 100의 분포 비율이 높아 주로 사용되는 난연제 제품 Penta-BDE (DE 71, 70-5DE)의 영향을 직접적으로 받은 것으로 보인다. ${ }^{12-14}$

\section{3. 실내 먼지 중 $\mathrm{PBDEs}$ 함유특성 고찰}

실내 먼지 중 $\mathrm{PBDEs}$ 를 분석한 결과 주로 $\mathrm{BDE}-$ $206,207,209$ 3종이 검출되었으며, 이중에서 특히 $\mathrm{BDE}-209$ 이 거의 대부분을 차지하고 있는 것으로 나 타났다. 그러므로, 먼지 중에서 검출된 BDE-209 이외 의 이성체에 대해서는 다른 상품의 사용에 의해서보 다는 BDE-209의 환경 중 분해 결과로 판단된다. 현재 주로 사용되고 있는 Deca-BDE는 사용과정 중에 다음 의 Fig. 4와 같이 시간이 경과됨에 따라 탈브롬화되어 다양한 이성체의 PBDEs가 먼지 중에서 검출될 수 있 다. Hua 등 ${ }^{15}$ 은 실제 태양광을 가지고 시간별로 분해 산물을 확인한 결과 최종적으로 삼브롬화물 또는 사 브롬화물까지 분해된다고 보고한 바 있다. 이를 토대 로 볼 때, 먼지 중에서 검출된 BDE-209 외의 이성체

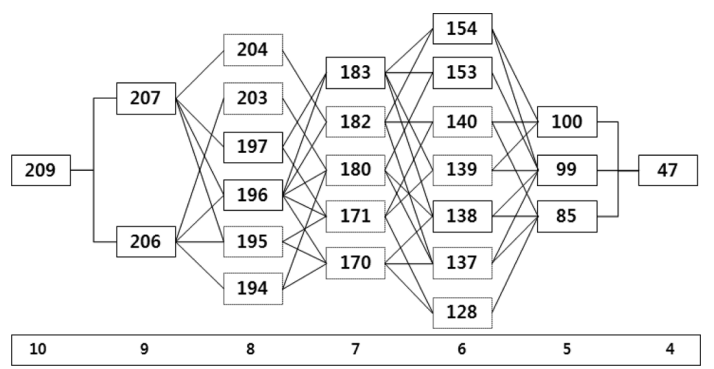

Fig. 4. Debromination of Deca-BDE. ${ }^{13}$ 
는 그 비율이 높지 않아서 직접적인 제품(Penta 또는 Octa)의 영향보다는 환경 중 분해의 결과로 판단된다.

\section{4. 결 론}

본 연구에서는 국제적으로 관심의 대상이 되고 있 는 브롬화난연제의 효율적인 관리를 위하여 가정에서 사용하고 있는 전기전자제품에 함유된 브롬화난연제 가 우리의 생활에서 어떻게 배출되는지 파악하고자 집에서 발생되는 먼지 시료를 채취 - 분석하여 배출특 성을 조사하였다.

아파트에서 채취한 4건의 시료와 실험실에서 채취 한 1 건의 실내 먼지 중 총 22 종의 PBDEs (BDE-47, $49,66,71,77,85,99,100,119,126,138,153,154$, $156,183,184,191,196,197,206,207,209)$ 를 분석 하여 정량한 결과, 아파트 실내 먼지에서 검출된 PBDEs 농도는 $35.22 \sim 575.88 \mathrm{ng} / \mathrm{g}$ 으로 나타났으며, 실 험실에서 겨울에 채취된 먼지 중에서는 PBDEs가 $524.44 \mathrm{ng} / \mathrm{g}$ 검출되었다. 실내 먼지 중 22종의 PBDEs 분석결과, 시료 중 $1 \mathrm{ng} / \mathrm{g}$ 이상 검출된 이성체는 BDE-47, 153, 183, 196, 197, 206, 207, 209 등 8종으 로 조사되었으며, 모든 분석 시료에서 검출된 주요 3 종의 이성체(BDE-206, 207, 209)의 분포특성을 보면, BDE-209가 69.1 $86 \%$ 로 배출되었으며, BDE-207이 $6 \sim 13 \%$ 그리고 BDE-206이 4 12\% 범위로 배출되었 다. 특히 미국의 실내 먼지에서는 BDE-47이 차지하 는 비율이 높아 국내의 검출패턴과는 다르게 나타났 으나, 중국은 BDE-209가 주로 배출되어 국내의 검 출패턴과 일치하는 것으로 조사되었다. 국내의 분석 한 먼지 시료의 이성체 패턴은 BDE-209의 비율이 5 개 시료 평균 $78.4 \%$ 차지하고 있어 대부분 Deca$\mathrm{BDE}$ 로 구성된 $102 \mathrm{E}(96 \%$ 이상)나 $82-\mathrm{OED}(91 \%$ 이 상)의 영향을 받은 것으로 판단되었다. 그러므로 본 연구결과 먼지 중에서 검출된 BDE-209 외의 이성체 는 그 비율이 높지 않아서 직접적인 제품(Penta 또 는 Octa)의 영향보다는 환경 중 분해의 결과로 판단 된다.

\section{참고문헌}

1. Ministry of environment, Persistent Organic Pollutant Management Law, 2012.

2. B.-H. Kim and J.-Y. Lee, KIC News, 13(5), 1-10 (2010).

3. Ministry of environment, Regulation Status of Brominated Flame Retardant, 2005.

4. S. Batterman, C. Godwin, S. Chernyak, C. Jia and S. Charles, Environ. Int., 36(6), 548-556 (2010).

5. H. A. Jones-Otazo, J. P. Clarke, M. L. Diamond, J. A. Archbold, G. Ferguson, T. Harner, G. M. Richardson, J. J. Ryan and B. Wilford, Environ Sci Technol., 39(14), 5121-5130 (2005).

6. Y. W. Wang, G. B. Jiang, P. K. S. Lam and A. Li, Environ. Int., 33(7), 963-973 (2007).

7. Ministry of environment, Korean Official Test of POPs, 2011.

8. B. H. Wilford, M. Shoeib, T. Harner, J. Zhu and K. C. Jones, Environ. Sci. Technol., 39(18), 7027-7035 (2005).

9. Y. Huang, L. Chen, X. Peng, Z. Xu and Z. Ye, Chemosphere, 78(2), 169-174 (2010).

10. A. Sjödin, O. Päpke, E. McGahee, J.-F. Focant, R. S. Jones, T. Pless-Mulloli, L.-M. L. Toms, T. Herrmann, J. Müller, L. L. Needham and D. G. Patterson Jr., Chemosphere, 73, S131-S136 (2008).

11. H. M. Stapleton, N. G. Dodder, J. H. Offenberg, M. M. Schantz and S. A. Wise, Environ. Sci. Technol., 39(4), 925-931 (2005).

12. M. J. La Guardia, R. C. Hale and E. Harvey, Environ. Sci. Technol., 40(20), 6247-6254 (2006).

13. H. Stuart, C. Ibarra, M. A. Abdallah, R. Boon, H. Neels and A. Covaci, Environ. Int., 34(8), 1170-1175 (2008).

14. G. Suzuki, K. Nose, H. Takigami, S. Takahashi and S. Sakai, Organohalogen Compounds, 68, 1843-1846 (2006).

15. J. Bezares-Cruz, C. T. Jafvert and I. Hua, Environ. Sci. Technol., 38(15), 4149-4156 (2004). 